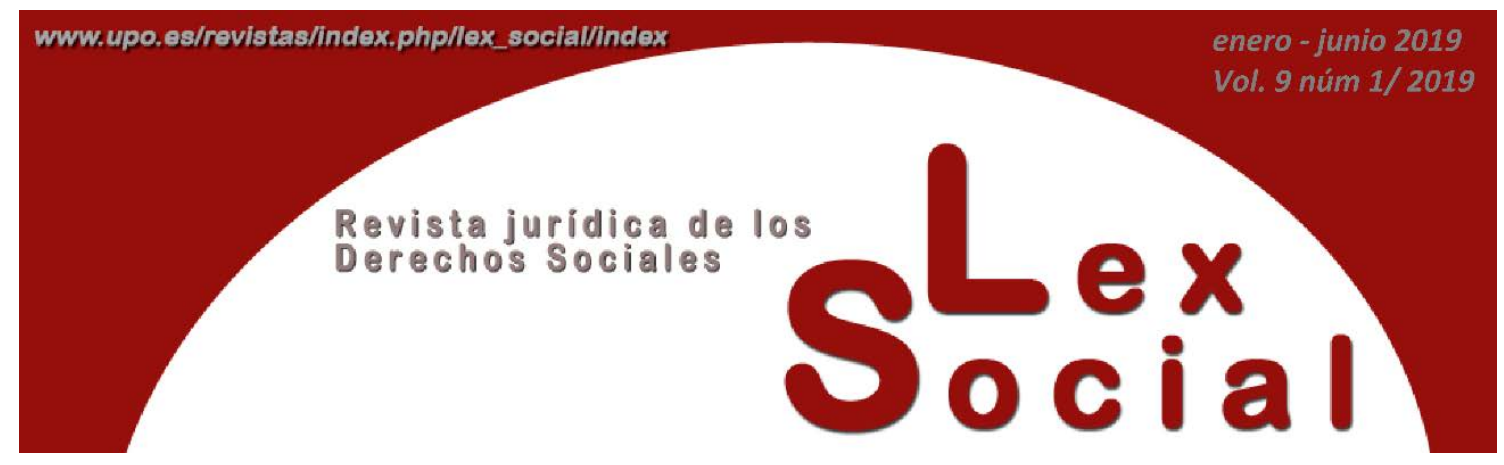

\title{
ACCIDENTES DE CONTAMINACIÓN EN PLATAFORMAS MARINAS: ¿CAMBIO DE PARADIGMA AMBIENTAL?
}

MARINE PLATFORMS POLLUTION ACCIDENTS: CHANGE OF ENVIRONMENTAL PARADIGM?

VIOLETA S. RADOVICH ${ }^{1}$

Artículo recibido el 25 de septiembre de 2018

Artículo aceptado el 15 de octubre de 2018

\section{RESUMEN}

El objetivo del presente artículo consiste en analizar los informes de las Comisiones designadas por los respectivos Gobiernos para investigar los accidentes ocurridos en las plataformas marinas Montara en el Mar Timor en la Zona Económica Exclusiva (ZEE) australiana y en la plataforma Deepwater Horizon en el Golfo de México. Particularmente, se analiza si a partir de estos accidentes se ha generado un cambio de paradigma ambiental en la sociedad.

Palabras Clave: Ambiental-accidente-plataformas -marinas-informes

\section{Abstract}

The objective of the article is to analyze the reports elaborated by the National Commissions designed by the respective Governments to investigate the accidents that took place in the marine platforms Montara in the Timor Sea in the Australian Economic Exclusive Zone (EEZ) and in Deepwater Horizon in the Mexico Gulf. It

\footnotetext{
${ }^{1}$ CONICET (Consejo Nacional de Investigaciones Científicas y Ténicas) - Instituto de Investigaciones Jurídicas y Sociales Ambrosio L. Gioja, Facultad de Derecho, UBA.
} 
is especially analyzed whether these accidents contributed to introduce a change of the environmental paradigm in society.

KEY WORDS: Environmental-accident-marine - platforms-reports

SUMARIO

1. La exploración y explotación de hidrocarburos en el mar.

2. El accidente en la Plataforma Deepwater Horizon.

2.1. Mejorar la Seguridad de las Operaciones extractivas en el Mar: el Rol del Gobierno.

2.1.1. La Oficina de Seguridad.

2.1.2. La Oficina de Concesiones y Ciencia Ambiental.

2.1.3. La Oficina de Administración de los Recursos Financieros.

2.2. Mejorar la Seguridad de las Operaciones extractivas en el Mar: el Rol de la Industria.

2.3. La Protección del Ambiente.

2.3.1. Tiering.

2.3.2. Exclusiones Categóricas.

2.3.3. Concesión de áreas extensas.

2.3.4. Guía NEPA.

2.3.5. Evaluación y gestión del riesgo.

2.4. Mejorar la planificación y la capacidad de respuesta.

2.5. Mejorar la capacidad de contención de los Pozos.

2.6. Superar los Impactos del Derrame y Restaurar el Golfo.

2.7. El aseguramiento de la Responsabilidad Financiera.

2.8. El compromiso del Congreso para asegurar la perforación eficiente en el Mar.

3. El accidente de la Plataforma Montara.

4. ¿Cambio de paradigma ambiental?.

5. Conclusiones. 


\section{La exploración y explotación de hidrocarburos en el mar}

Hasta la Segunda Guerra Mundial no se realizaron exploraciones en el mar. En 1880 se perforaron pozos de escasa profundidad en California. En 1920 se descubrieron en esa misma zona y en Laguna Maracaibo yacimientos de mayor importancia. Después de la Segunda Guerra Mundial, se intensificó la búsqueda y se perforó el primer pozo marino a $30 \mathrm{~km}$ de la Costa de Louisiana, en EE.UU (Comisión, 2011). Los excesivos costos desalentaron esta clase de exploración. La técnica ha evolucionado y actualmente un tercio del petróleo y un cuarto del gas natural que se consumen a nivel mundial provienen del mar (Roach, 2010). En 2001, había más de 8000 plataformas marinas y 700 pozos de exploración ubicados en unos 5000 yacimientos marinos a lo largo de más de cien países (Esmaeli, 2001 citado por Ferrara, 2015). Courteau (2011) citado por Silva Oliveira \& Silva Savio (2015, p.170), sostiene que hay más de 15.000 plataformas petrolíferas marinas en el mundo y que cada vez existe un mayor número de proyectos de perforación superiores a los 1000 metros de profundidad.

Los hidrocarburos han desatado guerras, a la Primera Guerra Mundial se la denominó "guerra del petróleo”, Japón invadió Pearl Harbor para proteger su flanco mientras se apoderaba de los recursos petrolíferos de las Indias Orientales, así como Hitler tenía como objetivo estratégico invadir la Unión Soviética y adueñarse de los campos petrolíferos del Cáucaso (Nonna, 1998).

Hasta que se encuentre alguna fuente alternativa, el petróleo seguirá afectando la economía mundial, sus oscilaciones en los precios acrecentarán economías o por el contrario, producirán inflación y recesión, en la actualidad la humanidad depende del petróleo para desarrollar las actividades cotidianas (Nonna, 1998). En este mismo sentido, la Comisión que estudió el accidente de la Plataforma Deepwater Horizon ${ }^{2}$ propiedad de la compañía British Petroleum (BP) en el Golfo de México al preguntarse por qué una compañía se encontraba perforando en la búsqueda de petróleo en aguas profundas a 49 millas marinas de la costa de Luisiana, respondió que se debía a que el pueblo estadounidense consume actualmente una gran cantidad de productos del petróleo (aproximadamente 18.7 millones de barriles por día). Asimismo, la Comisión (2011)

\footnotetext{
${ }^{2}$ Comisión Nacional del Derrame de Hidrocarburos de la Plataforma BP Deepwater Horizon y Perforación en el mar, "Deep Water. El Desastre de Hidrocarburos en el Golfo y el Futuro de la Perforación en el Mar. Informe al Presidente. Recomendaciones de la Comisión Nacional del Derrame de Hidrocarburos de la Plataforma BP Deepwater Horizon y Perforación en el Mar”. EE.UU, 2011.

Recuperado

de https://cybercemetery.unt.edu/archive/oilspill/20121210200707/http://www.oilspillcommission.gov/sites/ default/files/documents/OSC_Deep_Water_Summary_Recommendations_FINAL.pdf [Consulta: julio de 2017].
} 
explicó que a pesar de que se está trabajando para mejorar la eficiencia de los combustibles de los vehículos y en el desarrollo de combustibles alternativos, aún no se podrán dejar de lado estos recursos marinos en el futuro cercano.

El petróleo tiene un doble carácter, es un recurso natural no renovable que debe ser preservado y también es un elemento que contamina el ambiente y en tal sentido es un arma poderosa, no sólo como factor de poder y presión internacional sino también como instrumento bélico (Nonna, 1998).

La etapa de la exploración es un proceso complejo que comprende tres fases. La primera etapa es la realización de la cartografía geológica, que es un muestreo de rocas y su correspondiente análisis. La segunda etapa consiste en la utilización de la información obtenida en la llamada prospección sísmica. Finalmente, en la tercera etapa se realiza la perforación propiamente dicha.

En la primera etapa se utilizan la fotografía aérea y las imágenes satelitales. Cuando el reconocimiento inicial delimita una zona con probabilidades de entrampamiento, comienzan los estudios sísmicos. En el mar, se utilizan buques sísmicos que arrastran hidrófonos receptores de las ondas de rebote generadas por cargas de aire comprimido aplicadas sobre el agua. Toda la información aportada por procedimientos geológicos y geofísicos es analizada e interpretada por expertos para decidir si se justifica la perforación de pozos exploratorios en la zona estudiada (Nonna, 1998).

Finalmente, en la fase de perforación en el mar, varios pozos exploratorios son ubicados en zonas posibles utilizando equipos sofisticados, el proceso es complejo y costoso (Nonna, 1998).

Las plataformas que se utilizan para explorar y explotar hidrocarburos en el mar son comunmente denominadas "offshore”, su traducción al español generalizada es "costaafuera”. El término "offshore” es un adjetivo que significa "alejado o a una distancia de la costa" ${ }^{3}$. Fue adoptado para describir algo opuesto a "onshore” que significa "en la costa"; sin embargo, el término "offshore" identifica a estas plataformas desde una perspectiva basada en la costa, no en el mar, por lo que sostengo que no transmite adecuadamente los desarrollos recientes en la exploración del lecho y el subsuelo marino (Radovich, 2016).

En un comienzo la exploración se realizaba próxima a la costa, pero en los últimos ochenta años comenzó a realizarse en las aguas profundas debido a las innovaciones tecnológicas. Esta particularidad tiene implicancias en las medidas ambientales de seguridad, que deben ser apropiadas a las técnicas que se van desarrollando, especialmente aquellas técnicas que se emplean en las aguas más profundas, que están sujetas a los efectos de la alta presión que aumenta a mayor profundidad en el mar. De

\footnotetext{
${ }^{3}$ Diccionario Cambridge.
} 
hecho, las plataformas en cuestión están ubicadas en el ambiente marino, no "fuera de la costa”, por lo que planteo que se debería considerar a las plataformas desde el punto de vista marino, no desde el terrestre ni el costero.

En los primeros intentos de regulación de la temática, no se utilizaba el término “offshore”. Por ejemplo, el primer intento regulatorio, la Convención sobre Responsabilidad Civil por Contaminación por Hidrocarburos resultante de la Exploración y Explotación de los Recursos Minerales del Lecho Marino (CLEE 1977)4, no empleaba el término "offshore”; sino que se refería al "lecho submarino" (art. 2.1).

En idioma español se utiliza la expresión "costa afuera”, por ejemplo en un reciente decreto uruguayo denominado "Bases para el proceso de selección de empresas petroleras para la exploración y explotación de hidrocarburos en costa afuera de la República Oriental del Uruguay (Ronda Uruguay II)" ${ }^{5}$. Del mismo modo, se ha adoptado la expresión "mar adentro", un ejemplo es el Convenio Internacional sobre Preparación, Cooperación y Lucha contra la Contaminación por Hidrocarburos (OPRC 1990) ${ }^{6}$. Sostengo que la utilización de la expresión "mar adentro" es redundante, el mar es mar justamente, no es necesario aclarar que algo sucede dentro del mar, si es mar está dentro, sino lo es está afuera, y no será mar, sino costa o tierra. Es necesario llamar al recurso natural “mar” por su nombre. En este sentido, desde un punto de vista lingüístico, es más apropiado utilizar la formulación positiva de los términos, no la negativa (como se realiza con “off” y “afuera”). La presente es una invocación a llamar llanamente a las cosas por su nombre, por lo que son, no por lo que no son.

Agrego que la utilización del adjetivo “offshore” aplicado a la exploración y explotación del lecho submarino no transmite en la actualidad apropiadamente el significado de esta actividad desde el enfoque del desarrollo sostenible y el enfoque ecosistémico, ambos enfoques adoptados por la Convención sobre la Diversidad Biológica (CDB) ${ }^{7}$. La CDB considera a los ecosistemas marinos ${ }^{8} \mathrm{y}$ al ambiente marino ${ }^{9}$ como críticos para la protección de la biodiversidad, como lo demuestra el hecho de que uno de sus programas temáticos, el Mandato de Yakarta está basado en seis principios, entre ellos el enfoque

\footnotetext{
${ }^{4}$ Convención de Responsabilidad Civil por Daño por Contaminación por Hidrocarburos resultante de la Exploración y Explotación de Recursos Minerales del Lecho Marino (“CLEE 1977”), adoptada 1 mayo 1977 (no está en vigor).

${ }^{5}$ Uruguay. Decreto reglamentario 316/11, Aprobación de las Bases para el proceso de selección de empresas petroleras para la exploración y explotación de hidorcabruros en costa afuera de la República Oriental del Uruguay para la Ronda Uruguay II, que incluyen el respectivo modelo de contrato. Registro Nacional de Leyes y Decretos, tomo 1, semestre 2, 28/10/2011.

6 Convenio Internacional sobre Cooperación, Preparación y Lucha contra la Contaminación por Hidrocarburos (“OPRC 1990”), adoptado 30 de noviembre de 1990, 1891 UNTS 51 (entró en vigor 13 de mayo de 1995).

${ }^{7}$ Convención sobre la Diversidad Biológica (“CDB”), adoptada 5 junio de 1992, 1760 UNTS 79 (entró en vigor 29 de diciembre de 1993).

${ }^{8}$ Art. 2 CDB.

${ }^{9}$ Art. 22.2 CDB.
} 
ecosistémico, que aumenta el enfoque tradicional de mono-especies de protección ambiental. En la práctica, el enfoque ecosistémico significa que la conservación y el uso sostenible de la diversidad biológica deben ser tratados de una manera holística que se extienda a factores socio-económicos y culturales ${ }^{10}$. Lo relevante es que la CDB utiliza los términos “mar” y "marino”, en ningún momento se refiere a lo "offshore”, en esta línea de pensamiento en la presente tesis se toma la postura de referirse a las plataformas “marinas”, no así a las plataformas “offshore” y a la exploración y explotación en el mar, no así a la exploración y explotación “offshore”.

En esta línea de pensamiento, en EE.UU., la agencia denominada Minerals Management Service (MMS, Servicio de Gestión de Minerales) antes del accidente en la plataforma Deepwater Horizon, pasó a llamarse Bureau of Ocean Energy Management, Regulation, and Enforcement (BOEMRE, Oficina de Gestión, Regulación y Cumplimiento de la Energía Oceánica) luego del accidente. Es decir que, la nueva denominación institucional incluye el término “océano” en su denominación, no así el término “offshore”, ni “minerales”; el Océano ha sido colocado en primer plano.

Hay dos tipos principales de plataformas marinas, las plataformas de perforación y las plataformas de producción. Las plataformas de perforación son utilizadas en una primera instancia como su nombre lo indica para perforar los pozos, las plataformas Montara y Deepwater Horizon eran, por ejemplo, plataformas de perforación. Las plataformas de producción se utilizan después de que los pozos son perforados y sellados y son más estables que las plataformas de perforación ya que no se encuentran precisamente perforando, impactando sobre el lecho marino ${ }^{11}$.

\section{El accidente en la Plataforma Deepwater Horizon}

En el primer capítulo del informe de la Comisión se detallan los hechos que dieron lugar al accidente. Se explica que el pozo Macondo era un pozo difícil, que todos los pozos tienen "su personalidad” y lo describen con el juego de palabras en inglés: "a well like the hell”, la traducción en español es "un pozo como el infierno”.

El 22 de mayo de 2010, el entonces Presidente de EE.UU., Barack Obama anunció la creación de una Comisión Nacional, independiente, no partisana, destinada a emitir una opinión imparcial sobre el accidente en la plataforma perforadora Deepwater Horizon. El Presidente solicitó a la Comisión que determinara las causas del desastre, que mejorara la habilidad del país para responder a los derrames y que recomendara las reformas

10 “The Jakarta Mandate- from global consensus to global work". Convention on Biological Diversity publication.

Recuperado de https://www.cbd.int/doc/publications/jm-brochure-en.pdf [Consulta: julio de 2017].

11 'Gulf Platform Investigators Focus on Blast Cause’ CBS News (2 septiembre 2010).

Recuperado de http://www.cbsnews.com/stories/2010/09/02/national/main6829893.shtml [Consulta: julio de 2017]. 
necesarias para lograr que la producción de energía de exploración y explotación marina sea más segura.

La Comisión trabajó durante seis meses y preparó un Informe dividido en las siguientes áreas principales:

1) La mejora de la Seguridad de las Operaciones extractivas en el Mar: el Rol del Gobierno.

2) La mejora de la Seguridad de las Operaciones extractivas en el Mar: el Rol de la Industria.

3) La protección del Ambiente.

4) El refuerzo de la planificación y la capacidad de respuesta ante el derrame de petróleo.

5) La mejora de la capacidad de contención de los Pozos.

6) La superación de los Impactos del Derrame y la restauración del Golfo.

7) El aseguramiento de la responsabilidad financiera.

8) El Compromiso del Congreso para asegurar la perforación eficiente en el Mar.

\section{Fotografía $N^{\circ} 5$}

\section{Comienza la explosión en la plataforma Deepwater Horizon}

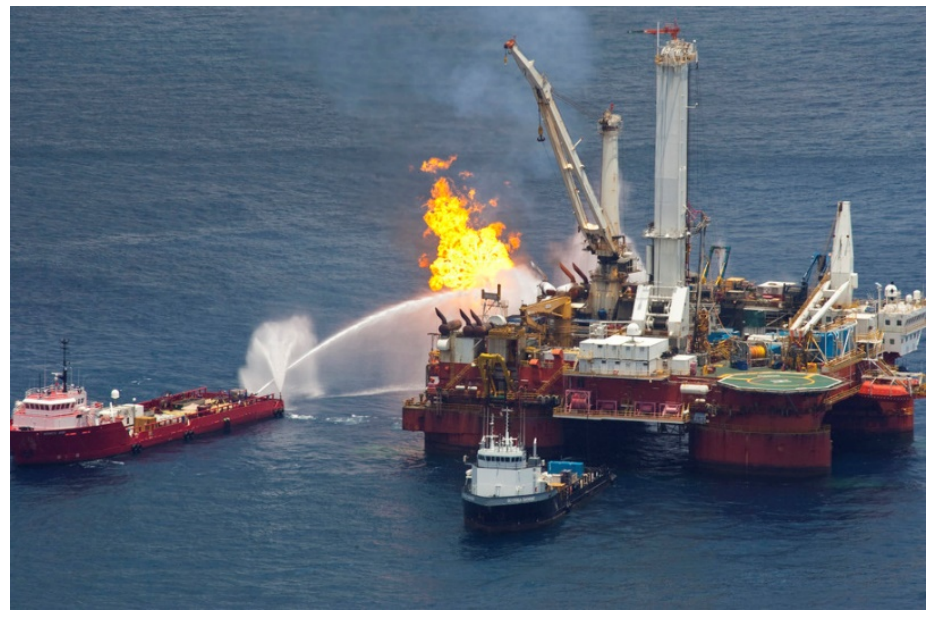

Fuente:https://www.rt.com/usa/324653-bp-oil-spill-charges/

Fotografía $N^{\circ} 6$

El accidente en la plataforma Deepwater Horizon 


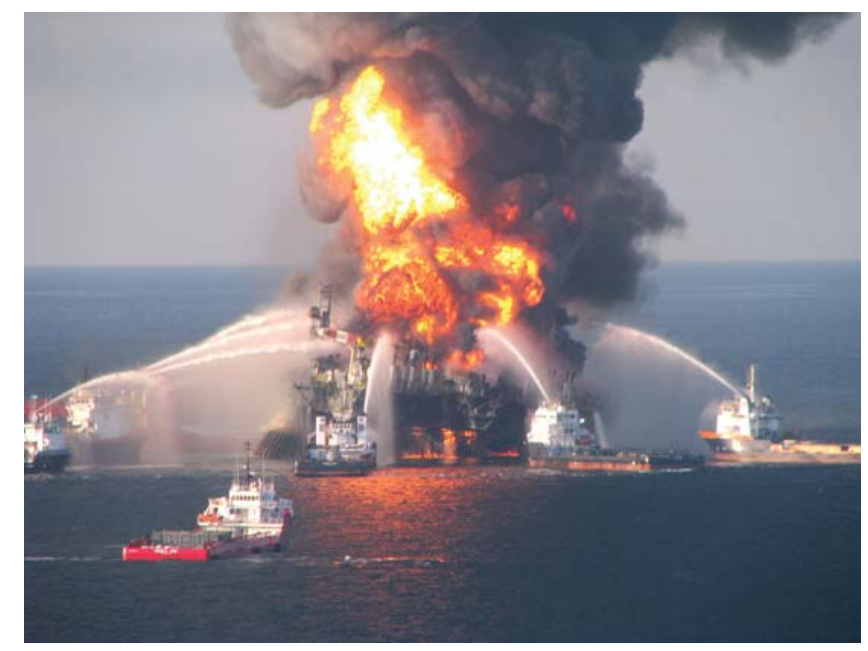

Fuente: http://www.chul.erds.co/bp-oil-spill-essay.html

La plataforma Deepwater Horizon era una plataforma semisumergible de propiedad de Transocean, una compañía fundada en 1919 en el Estado de Luisiana y actualmente una de las contratistas más grandes en el rubro. En 2009, la flota de Transocean producía 11.6 mil millones de Dólares de ganancias, había consolidado su posición dominante en la industria a fines de 2007, cuando se unió con su rival Global Santa Fe. La construcción de la plataforma Deepwater Horizon costó 350 millones de Dólares y era considerada la mejor perforadora de la flota, el fletamento de sus servicios tenía un valor de 1 millón de Dólares por día. Desde el año 2001 había sido fletada a la compañía con base en Londres, British Petroleum (BP) (Comisión, 2011).

La plataforma contaba con 126 personas aproximadamente a bordo: 80 eran empleados de Transocean, algunos de BP, otros eran empleados de la cafetería y la lavandería, y un grupo temporario de trabajadores eran contratados para labores específicos, muchos de ellos ingenieros con distintas especialidades. Las oficinas y las viviendas estaban en las dos cubiertas superiores de las perforadoras. Asiduamente sobrevolaban helicópteros con trabajadores y suministros que aterrizaban en el helipuerto ubicado en la cubierta superior. La plataforma flotaba a 4992 pies del agua, justo detrás de la suave pendiente de la plataforma continental en el Cañón de Misisipi (Comisión, 2011).

La perforación de hidrocarburos siempre ha sido una tarea complicada que combina maquinaria pesada e hidrocarburos volátiles que se extraen a altas presiones. La alta presión en las profundidades marinas es el principal obstáculo que afronta la exploración y explotación de hidrocarburos en el mar. En el Golfo de México, desde 2001, entre las 35.000 personas que trabajan en 90 plataformas perforadoras y en 3.500 plataformas de producción, ha habido 1.550 heridos, 60 fallecidos y 948 casos de incendios y explosiones, hasta el momento de la redacción del Informe (Comisión, 2011).

"La plataforma perforadora nunca dormía” se explica en el Informe, la mayoría de los trabajadores tienen jornadas de trabajo de doce horas, trabajan tres semanas y luego 
cuentan con tres semanas de franco. Los sueldos son altos debido a que se trata de un trabajo peligroso y alejado del hogar, las personas que tienen los puestos más altos cobran salarios de seis dígitos.

La Comisión documentó las debilidades de la regulación y el control federal y realizó recomendaciones sobre modificaciones que deberían realizarse en torno a las autoridades legales, las regulaciones y las inversiones en experticia y gestión.

“Tanto el Gobierno como la industria fallaron en anticipar y prevenir esta catástrofe y fallaron también en la preparación para responder una vez que había sucedido" (Comisión, 2011, p.ix).

"La mayor parte del pueblo estadounidense disfruta de los beneficios que la energía brinda para el transporte, pero no aprecia los riesgos directos que conlleva su producción. Los humedales de Luisiana han sufrido durante décadas su alteración destructiva para que la exploración de petróleo pudiera ser llevada adelante” (Comisión 2011, p. x).

El accidente empezó a desarrollarse cuando se estaba finalizando de tapar con cemento la parte superior del pozo, es decir, ya se había concluído la etapa de perforación a 13000 pies bajo el lecho marino y se procedía al cierre hasta la posterior instalación de la plataforma de producción para dar comienzo a la extracción de hidrocarburos. El resto del día durante el cual comenzó el accidente, estuvo dedicado a realizar más evaluaciones en el pozo, pruebas positivas y negativas de presión para preparar este cierre que se conoce en la jerga técnica con el nombre de "abandono temporario”.

En el informe de la Comisión se detalla que parecía que todo iba bien hasta ese momento, aunque llevaban un atraso de seis semanas y se había excedido el presupuesto en más de 55 millones de Dólares. Justamente, si esta etapa finalizaba correctamente, podrían ahorrarse el costo que implicaba que tres especialistas viajaran a realizar una evaluación del estado del cemento, ya que generalmente esta evaluación se realiza una vez que se reabre el pozo para comenzar la etapa de producción, entonces la compañía se ahorró esta contratación, es decir, se “ahorró” los honorarios de un valor de \$128.000 Dólares. Ya se habían perforado 13.000 pies bajo el lecho marino, la Comisión (2011) explica que esta actividad se asemeja a la exploración del espacio exterior.

La situación empezó a complicarse cuando se llevó adelante el test negativo de presión. El tubo de perforación continuaba exhibiendo presión elevada; sin embargo, finalmente, dio buenos resultados. No obstante, de un momento a otro, comenzó a salir lodo a través del cemento, luego hubo una explosión y se inició el fuego en la banda de estribor de la torre de perforación. Mucha gente resultó herida, se ordenó abandonar la plataforma, de los 115 sobrevivientes, 16 tenían heridas graves. Treinta y seis horas después de la primera explosión, la plataforma se hundió. Paradójicamente fue el 22 de abril, el día de la Tierra (Comisión, 2011). 
La explosión de la plataforma comenzó un desastre humano, económico y ambiental. Cuatro millones de barriles de petróleo empezaron a contaminar el Golfo. Todavía no se contabilizaron los costos del accidente, pero ya está claro que el impacto en los sistemas naturales de la región y en la sociedad fue enorme, y que los costos económicos ascendieron a diez mil millones de Dólares (Comisión, 2011).

La primera conclusión a la que arribó la Comisión es que el accidente se podría haber prevenido ya que las causas inmediatas de la explosión del pozo Macondo se debieron a errores identificados por parte de BP y Transocean que revelan que dichas fallas eran sistemáticas, por lo que ponen en dudas la cultura de seguridad de toda la Industria.

A continuación, se resumen las principales áreas del Informe.

\subsection{Mejorar la Seguridad de las Operaciones extractivas en el Mar: el Rol del Gobierno}

La Comisión (2011) concluyó que se requiere una reforma normativa e institucional para lograr la gestión ambiental de la exploración y explotación de hidrocarburos en el mar. Se necesita una reforma fundamental en la estructura de las instituciones que están a cargo del control regulatorio y en el proceso interno de toma de decisiones para garantizar la autonomía política, especialidad técnica y la absoluta consideración sobre la protección ambiental.

La experiencia en torno a la restauración de otras áreas sensibles, como los Grandes Lagos, o los Everglades, indica que para progresar se requieren acciones federales y estaduales coordinadas, un fondo de financiamiento, control a largo plazo, ciudadanía comprometida con el apoyode grupos no gubernamentales e investigación científica, entre otros requisitos (Comisión, 2011).

"Nadie puede eliminar todos los riesgos asociados con la exploración en aguas profundas. Pero cuando se decide realizar la exploración, más que nada en ambientes sensible como el Golfo de México o el Ártico, el Estado tiene la obligación de tomar decisiones responsables en lo que respecta a los beneficios y los riesgos” (Comisión 2011, p.xi).

El entonces Presidente Barack Obama sostuvo que hay que llegar a un punto de equilibrio entre el interés de la energía del mar con la protección de los ambientes marinos y costeros y en este sentido antes de terminar su mandato en 2016, amplió el ya existente Monumento Nacional Papahanaumokuakea en el archipiélago de Hawaii, que ahora cuenta con una extensión marina de un millón y medio de kilómetros cuadrados.

Antes del accidente de la plataforma Deepwater Horizon, la oficina en ese entonces denominada Minerals Management Service, Servicio de Gestión de los Minerales (MMS) que dependía del Departamento del Interior, se encargaba de las actividades relativas a la exploración y explotación en el mar; la Comisión plantea que ahora se necesitan agencias independientes. La oficina MMS no sólo era responsable de la gestión de los recursos y 
del otorgamiento de las licencias para explorar y explotar en el mar, sino que también gestionaba las ganancias de las concesiones, realizaba las evaluaciones ambientales, revisaba los planes y emitía los permisos, llevaba adelante las auditorías y hacía cumplir las regulaciones ambientales y relativas a la seguridad. Esta superposición de atribuciones, hacía que la oficina MMS fuera más propensa a las presiones externas y llevaba a tensiones internas.

"La tensión se producía entre la manda en la Ley de la plataforma continental de 1978 acerca de promover el desarrollo de los recursos marinos y entre la manda de promover el cuidado del ambiente. Estas presiones externas hacían que se difirieran las decisiones a la industria, que se encargaba de acortar los plazos mediante la intervención política en el Congreso y retrasaba y debilitaba las regulaciones destinadas a mejorar la seguridad en el manejo de las operaciones”(Comisión, 2011, p. 255).

Además de la oficina MMS, otras oficinas del Departamento del Interior, así como los Departamentos de Transporte, Comercio, Defensa y Seguridad Interior y la Agencia de Protección Ambiental (EPA, por sus siglas en inglés) estaban involucrados en algunos aspectos de la actividad.

La Comisión decidió que se debían crear tres instituciones independientes, con tres atribuciones diferentes. El presupuesto para estas agencias debe provenir de las tarifas que paga la industria de exploración y explotación. Se debería establecer un mecanismo, incluso en las cláusulas de los contratos de concesión para el pago de honorarios regulatorios para lograr un financiamiento adecuado, estable y seguro de las agencias regulatorias -el Departamento del Interior, la Guardia Costera y la agencia NOAA-y para asegurar que puedan desarrollar sus obligaciones, otorgar permisos y revisiones cuando sea necesario y contratar ingenieros, inspectores y científicos experimentados.

Luego del accidente en la plataforma, la oficina MMS pasó a llamarse Bureau of Ocean Energy Management, Regulation and Enforcement (Oficina de Gestión, Regulación y Cumplimiento de la Energía Oceánica, BOEMRE, por sus siglas en inglés) y anunció un plan para dividir sus responsabilidades en tres agencias.

Una agencia será responsable del cumplimiento de la regulación ambiental y de la seguridad de la exploración y explotación en el mar, otra se dedicará a la concesión de los permisos enfocada en la ciencia ambiental, la última administrará las ganancias ${ }^{12}$.

Las siguientes son las denominaciones y atribuciones de las tres agencias:

\subsubsection{La Oficina de Seguridad}

12 Esta recomendación fue llevada a cabo en 2010, las tres agencias fueron creadas, ver: https://www.boem.gov/reorganization/ [Última consulta: julio de 2017]. 
Será responsable de controlar la integridad estructural y operativa de todas las instalaciones y actividades relacionadas con la producción de energía en el mar, tanto de la producción de hidrocarburos como de energías renovables, sus responsabilidades serán establecidas por ley especial. La oficina tendrá autoridad independiente sobre la seguridad técnica y operativa en todas las fases de los proyectos de desarrollo de energía en la plataforma continental, entre las que se incluyen, la planificación, el diseño, la construcción, la operación y el decomiso de las instalaciones, es decir se abocará a los aspectos no económicos de la actividad en la zona federal. También tendrá el rol de liderazgo en la coordinación con otros entes regulatorios con autoridad independiente sobre la actividad, como las agencias EPA y NOAA y la Guardia Costera. Sus responsabilidades principales, entre otras, serán las siguientes:

- Revisar y aprobar o denegar todos los permisos de exploración, desarrollo y producción.

- Inspeccionar,sin previo aviso, las operaciones en el mar mediante un equipo de expertos en inspecciones planificadas.

- Evaluar la elegibilidad de los concesionarios con basamento en las calificaciones ambientales y relativas a la seguridad.

- Revisar y aprobar la seguridad y la factibilidad de las actividades de mitigación ambiental establecidas en la ley ambiental nacional National Environmental Policy Act (NEPA), los documentos, otras consultas ambientales y autorizaciones además de ejecutar dichos requisitos durante la duración de la operación.

- Elaborar un código de normas sobre la integridad estructural, procedimental y de seguridad laboral para reemplazar las regulaciones basadas en el desempeño (denominadas “safety case” en inglés, “caso de seguridad”).

- Realizar la revisión técnica del programa de licitación de cinco años.

- Realizar la revisión técnica de los planes de respuesta ante derrames y de los planes.

- Investigar todos los accidentes y otros eventos significativos que podrían haber sido catastróficos.

La organización y la composición de los empleados de la Oficina será decidida durante un proceso de transición en el que las áreas y las actividades se analizarán y categorizarán según el riesgo. El Director deberá ser un profesional idóneo con conocimiento técnico o del ámbito de la ingeniería y será designado por el Presidente de la Nación por un período de cinco o seis años y confirmado por el Senado, las escalas salariales serán similares a las de la Comisión Regulatoria Nuclear.

\subsubsection{La Oficina de Concesiones y Ciencia Ambiental}

Funcionará como la oficina de gestión de los recursos renovables y de otros recursos minerales de la Plataforma Continental. Estará encargada de la promoción del desarrollo 
ambientalmente responsable y eficiente de la plataforma continental. Sus atribuciones principales, entre otras, serán las siguientes:

- Realizar los procesos de planeamiento de las actividades en la plataforma continental, incluidos los programas de licitación de cinco años.

- Llevar adelante las licitaciones de la producción de hidrocarburos y de las estructuras de producción de energía renovable.

- Dictar regulaciones con respecto a los términos y condiciones de las licitaciones.

- Revisar y aprobar todos los planes de respuesta y contención de derrames y asesorar a la nueva autoridad de seguridad sobre consideraciones ambientales.

- Tomar decisiones sobre el manejo de los recursos, por ejemplo, el abandono de los reservorios, asuntos de reservorios compartidos y la optimización de la exploración y explotación de hidrocarburos.

- Revisar y aprobar los permisos para las actividades sísmicas.

- Realizar las revisiones que establece la ley NEPA durante las respectivas etapas y coordinar otras revisiones ambientales cuando fuera apropiado.

- Administrar el Programa de Estudios Ambientales.

La oficina tendrá dos secciones principales:

- una sección de licitación y evaluación de recursos y;

- una sección de ciencia ambiental, que será dirigida por un Jefe Científico, quien realizará todas las revisiones requeridas en la ley NEPA y administrará el Programa de Estudios Ambientales, entre otras tareas. El Jefe Científico también opinará sobre las zonas que se ofrecerán a licitación y sobre las acciones de protección y mitigación ambientales que se llevarán adelante en dichas zonas.

\subsubsection{La Oficina de Administración de los Recursos Financieros}

Se centrará exclusivamente en recolectar las ganancias, sin ningún tipo de injerencia en asuntos relativos a las autorizaciones o temáticas ambientales para evitar presiones externas. Se destinará una parte de las ganancias a la inversión en la generación de energías renovables marinas y a la restauración a largo plazo del Golfo de México.

\subsection{Mejorar la Seguridad de las Operaciones extractivas en el Mar: el Rol de la Industria}

El control regulatorio por sí solo no será suficiente para garantizar la seguridad adecuada, la industria del petróleo y el gas deberá tomar sus propias medidas para aumentar exponencialmente la seguridad en la Industria, deberá implementar los mecanismos de auto-regulación que complementen la aplicación de las normas del Estado (Comisión, 2011). 
La Comisión (2011) recomendó que se cree una nueva oficina de seguridad dentro de la Industria, que trabaje junto con organismos del Gobierno para definir nuevas prácticas y controlarlas y asegurar que no haya en la Industria compañías con estándares de seguridad menos estrictos que los requeridos.

Tanto el Gobierno como la Industria no estuvieron preparados para contener el accidente del pozo Macondo porque no contaban con un plan de contingencia adecuado y no habían invertido lo suficiente en investigación para mejorar la contención. La industria del petróleo y el gas, no había adoptado una cultura de seguridad. El accidente en el pozo Macondo revela que mientras que la Industria ha destinado billones de Dólares para las tecnologías necesarias para perforar en aguas profundas, casi no ha invertido dinero en crear capacidades alternativas para lidiar con las consecuencias previsibles de un desastre (Comisión, 2011).

Las compañías líderes en el sector de la exploración y explotación petrolera en el mar deben tomar la responsabilidad de readaptar las prácticas de la Industria y así crear una cultura de seguridad. La oficina debe lograr que se garantice la excelencia en el proceso de seguridad y debe reunir las siguientes características:

- Liderazgo e Incentivos: Los CEO’ s de la Industria y los miembros del directorio deben liderar la participación del resto de los empleados de todos los rangos.

- Auditoría: Será una de las funciones más importantes de la oficina.

- Evaluación: Luego de sus primeros cinco años de operación, la oficina será auditada por una entidad independiente para evaluar si se ha mejorado la cultura y las prácticas de seguridad y los resultados del proceso de seguridad.

Para contener un futuro accidente se requiere la coordinación de diversas actividades complejas que suceden simultáneamente. Para que este proceso sea exitoso -y de este modo ganar la confianza de la Industria, el Gobierno, los aseguradores y el público- los nuevos esfuerzos por parte de la Industria deben incluir una planificación extensiva, el desarrollo de escenarios de nuevos accidentes potenciales y la realización de ejercicios de perforación a escala completa. A medida que se desarrolla el equipamiento de nueva tecnología, la Industria debe asegurar que la tecnología de contención sea compatible con sus pozos.

Asimismo, la Comisión (2011) recomendó que la Industria estadounidense del petróleo y el gas debe cooperar internacionalmente para asegurar la seguridad y la preparación en las áreas de producción en el mar en el mundo. Del mismo modo, debe desarrollar capacidades a larga escala y contención, que incluyan el equipamiento, los procesos y la logística necesaria.

\subsection{La Protección del Ambiente}

La Comisión (2011) analizó los procesos de licenciamiento y autorización que siguió la oficina MMS en el Golfo de México antes del accidente de la Plataforma Deepwater 
Horizon y concluyó que se violaba sistemáticamente el proceso de análisis ambiental y que los requisitos que establecía la ley ambiental nacional National Environmental Policy Act (NEPA) para la exploración y explotación en el mar necesitaban una significativa revisión, en particular, los siguientes:

2.3.1. la aplicación del proceso denominado tiering,

2.3.2. el uso de las exclusiones categóricas,

2.3.3. el otorgamiento deconcesiones en áreas extensas, y

2.3.4. la omisión del desarrollo de una guía formal basada en las regulaciones de la ley NEPA.

2.3.1. Tiering: es el proceso establecido en la ley NEPA en el que se basaba la oficina MMS para la concesión de las áreas para la exploración y explotación en el mar. Se recurría a un estudio de impacto ambiental amplio para cubrir "temas generales" en un área extensa, mientras se establecía que los temas específicos de un sitio en particular o de áreas más pequeñas serían abordados mediante "análisis subsiguientes ambientales”. No obstante, en la práctica estos análisis subsiguientes ambientales no eran elaborados.

2.3.2. Exclusiones Categóricas: se establecían categorías de actividades que supuestamente no implicaban un efecto significativo en el ambiente, ni individual ni acumulativamente, y sobre las que por lo tanto no se requería una evaluación ni estudio ambiental. La oficina MMS históricamente aplicaba estas exclusiones a los planes de desarrollo y producción en el Golfo de México. Luego del derrame de BP Deepwater Horizon, es muy difícil sostener que la perforación en el mar no presenta algún riesgo potencial al ambiente del Golfo (Comisión, 2011). En consecuencia, en agosto de 2010 se anunció que se restringiría el uso de estas exclusiones.

2.3.3. Concesión de áreas extensas: fue solicitado por la Industria hace veinte años. Por ejemplo, el Estudio de Impacto Ambiental 2007-2012 en el Golfo de México cubrió más de 87 millones de hectáreas.

2.3.4. Guía NEPA: El BOEMRE se encuentra elaborando la guía que la oficina MMS omitió elaborar, que debería asegurar un nivel más alto de consistencia y transparencia de los requisitos establecidos en la ley NEPA en las diferentes regiones del país.

El Consejo de Calidad Ambiental y el Departamento del Interior deben revisar y reforzar las políticas, las prácticas y los procedimientos establecidos en la ley NEPA para mejorar el nivel de análisis ambiental, la transparencia y la consistencia en todas las etapas de planificación, concesión, exploración y desarrollo de la plataforma continental.

El Congreso debe reformar la Ley de la Plataforma Continental y extender el plazo para aprobar los planes de exploración de 30 a 60 días. La Oficina de Seguridad será la responsable de aprobar el diseño de los pozos y los planes de perforación. 
Asimismo, la Comisión (2011) se enfocó en la necesidad de la consulta entre las distintas agencias gubernamentales basada en la gestión integral del mar. La gestión integral del mar es lo opuesto a su gestión sectorizada; es decir enfocada sólo desde el sector de la pesca, de la navegación o de los hidrocarburos, sin interrelación entre ellos. La gestión integral del mar consiste en una visión omnicomprensiva del mar. Cicin-Sain, Vanderzwaag \& Balgos (2015) citados por OECD (2016, p. 225) sostienen que la gestión integral implica procesos para coordinar las acciones de las diversas agencias gubernamentales involucradas en los asuntos oceánicos.

Actualmente, la gobernanza del océano enfrenta numerosos riesgos e incertezas, entre los que se incluyen una gran fragmentación de agencias que estudian diferentes actividades, lagunas jurídicas, débil cumplimiento y ejecución de las normas y nuevos temas emergentes. Hay signos que indican que la gobernanza del océano seguirá creciendo en mayor medida sectorialmente, no mediante enfoques comprehensivos. Hay una clara necesidad de que la gestión del espacio oceánico sea más integral (OECD, 2016).

Las presiones sobre el ambiente oceánico son principalmente atribuidas a la gestión y regulación histórica ad hoc, es decir sectorizada de las actividades oceánicas.

Según la Ley de la Plataforma Continental, el Secretario del Interior es quien decide el balance entre la protección ambiental y el desarrollo de los recursos. Es decir, las sugerencias de otras agencias no son vinculantes para el Secretario del Interior, lo mismo sucede en la etapa de desarrollo y producción. Como resultado, la Agencia Nacional Oceánica y Atmosférica (NOAA) no tiene rol alguno en la selección de las áreas a conceder para la exploración y explotación de hidrocarburos en la plataforma continental. La Comisión (2011) estableció que se requiere un proceso de consulta interagencia formal con el objetivo de identificar aquellas áreas que deben ser excluidas de las concesiones debido a su alta importancia o sensibilidad ecológica. Otras agencias federales que deberían estar involucradas son el Servicio de Peces y Fauna Marina y la agencia de protección ambiental (EPA).

En este orden de ideas, el 19 de julio de 2010, el Presidente Barack Obama mediante el Decreto13547 estableció una nueva política nacional oceánica que incluye la regulación de la planificación espacial marina (PEM) así como un proceso comprehensivo, adaptativo, integrado, transparente, ecosistémico y basado en la ciencia para analizar el uso de los océanos, las costas y las áreas de los Grandes Lagos.

Asimismo, se decidió que se debe expandir el Sistema de Observación Integrada del Océano del Golfo de México, que incluye la instalación y el mantenimiento de una red de instrumentos in situ que se instalan en las plataformas de producción.

La Comisión (2011) afirma que la PEM tiene el potencial de mejorar la eficiencia y reducir los conflictos entre los usuarios del Océano, ya que se identifican cuáles son las áreas del océano apropiadas o inapropiadas para determinados usos. En el mismo sentido, la Comisión (2011) sostuvo que el Congreso debe financiar subsidios para el desarrollo 
de organismos regionales de planificación y que la gestión del Océano también debe incluir las áreas marinas protegidas (AMPs) estratégicas, incluidas pero no limitadas a Santuarios Nacionales Marinos, que pueden ser utilizadas como "bancos de mitigación” para ayudar a compensar el daño al ambiente marino.

Para asegurar que la exploración y explotación de hidrocarburos en el mar se lleve adelante de una manera que minimice los impactos adversos al ambiente, las decisiones sobre esta actividad deberán fundarse en sólidas bases científicas y se debe investigar en forma sistémica para aumentar la comprensión de los impactos de la actividad (Comisión, 2011).

La investigación será útil para otras actividades que se desarrollan en el mar, como ser el desarrollo de las energías renovables, por ejemplo, la energía eólica en el mar. A su vez, es crítico el control ecológico posterior para entender el impacto de las actividades y para facilitar un enfoque adaptativo a la gestión ambiental.

En EE.UU. rige la industria privada en el suministro de petróleo, gas y el resto de los tipos de energía, las empresas no son estatales ni son controladas por el Estado, como en muchos otros países. El sistema privado conlleva implicancias en la manera en que el gobierno estadounidense controla y regula la perforación en el mar, la ventaja es que se genera una industria competitiva con tecnología avanzada (Comisión, 2011).

\subsubsection{Evaluación y gestión del riesgo}

Por añadidura, se señala como una constante la falta de actualización sistemática de la evaluación del riesgo y de las herramientas de gestión de riesgo utilizadas como base para la regulación. La oficina MMS intentó adoptar bajo distintos gobiernos regulaciones que hubieran requerido a las compañías que gestionaran todas sus actividades e instalaciones bajo un sistema documentado denominado "Sistema de Gestión de Seguridad y Ambiental” (SEMS, por sus siglas en inglés). No obstante, nunca logró adoptarse por oposición de la Industria, recién se adoptó en septiembre de 2010, luego del accidente en la plataforma Deepwater Horizon.

Históricamente, no se ha requerido que la Industria informara las descargas sin control de hidrocarburos ni las denominadas “pérdidas pequeñas” (minimum losses, en inglés), a pesar de que ambas son indicadores de un alto potencial sobre accidentes de magnitud. Las agencias del Gobierno que regulan la exploración y explotación de hidrocarburos en el mar deben reorientar sus enfoques regulatorios para integrar prácticas más sofisticadas de evaluación y manejo del riesgo. Deben cambiar su enfoque centrado en regulaciones que cubren sólo al operador a regulaciones que se relacionen con el desarrollo integral del pozo, complementado con un enfoque proactivo, de desempeño basado en la gestión del riesgo que sea específico a las instalaciones, las operaciones y los ambientes (Comisión, 2011).

Este enfoque es similar al del "caso de seguridad” (safety case) que se utiliza en el Mar del Norte, que implica que el operador y los propietarios de la plataforma perforadora 
evalúen los riesgos asociados con la operación específica, desarrollen un plan coordinado para gestionar dichos riesgos, integren a todos los contratistas involucrados en el sistema de gestión de la seguridad y asuman la responsabilidad de desarrollar el proceso de gestión del riesgo.

Para cumplir con estos objetivos acerca del desarrollo de un nuevo enfoque de la evaluación y gestión del riesgo, la Comisión (2011) brinda las siguientes recomendaciones:

- El Departamento del Interior debería complementar el programa de gestión del riesgo con estándares prescriptivos de seguridad y prevención de la contaminación que sean desarrollados en cooperación con consultores internacionales y que sean al menos tan rigurosos como los términos de contratación y los requisitos regulatorios vigentes en los países productores de petróleo. Estos estándares deben ser aplicados en el Golfo de México, en el Ártico y a nivel internacional donde opere la industria de extracción de hidrocarburos en el mar. Los estándares deben ser actualizados al menos cada cinco años mediante el proceso formal de revisión de la Organización Internacional de Estandarización (ISO, por sus siglas en inglés).

- Las compañías interesadas en participar en la industria de la exploración y explotación de hidrocarburos en el mar deben demostrar tanto su competencia basada en la experiencia, como su capacidad financiera como pre-requisitos para poder participar en las licitaciones.

Para cultivar y mantener la experticia del Gobierno sobre la seguridad en la perforación en el mar se deben cumplir los siguientes pasos:

a) Establecer un procedimiento bajo los auspicios de la Academia Nacional de Ingeniería para identificar los criterios para la perforación de los pozos de alto riesgo y desarrollar metodología para evaluar dichos riesgos. Este proceso debe incluir la colaboración de expertos del Servicio Geológico, del Departamento de Energía, de la agencia NOAA y de la Academia. Asimismo, el Departamento del Interior debe desarrollar competencia interna para realizar estas sofisticadas evaluaciones del riesgo.

b) Establecer un esfuerzo de investigación coordinado, inter-agencia para desarrollar sistemas, equipos y prácticas más seguros para prevenir fallas, tanto de diseño como de equipamiento en el futuro. En EE.UU, se ha creado por ley el Programa de Recursos de Petróleo y otros recursos no convencionales de gas natural que gestiona la Secretaría de Energía enfocado en mitigar los riesgos de las operaciones en el mar.

c) Desarrollar requisitos detallados sobre la obligatoriedad de informar accidentes y datos concernientes a los accidentes, esto permitirá tener un mejor seguimiento y un mejor análisis de los riesgos. Estos informes deben estar disponibles al público y ser aplicables a todas las actividades de exploración en el mar, se deben incluir los accidentes vinculados a los helicópteros y los buques de abastecimiento tanto en plataformas perforadoras como de producción. 
d) Otorgar protección a los "buchones" que notifiquen a las autoridades sobre fallas en la seguridad, esta protección debería incluirse en la reforma de la Ley de las tierras de la plataforma continental y leyes relativas.

Las conclusiones de la Comisión con respecto a la exploración y explotación de hidrocarburos en el mar son las siguientes:

- El Congreso debe reformar la Ley de la Plataforma Continental para otorgar a la agencia NOAA un rol formal consultivo vinculante durante el desarrollo del plan de los cinco años en torno a la exploración y explotación de hidrocarburos. La agencia NOAA debe participar como máximo 60 días antes de que el Secretario del Interior otorgue los permisos, básicamente para realizar comentarios sobre aquellas áreas que deben excluirse de esta actividad o que deben ser tratadas de una manera especial debido a su sensibilidad ecológica, es decir, para expedirse sobre las AMPs. Las recomendaciones de la agencia NOAA deberían ser vinculantes para el Secretario del Interior, salvo que éste determine su inconsistencia con intereses de política nacional relevantes con fundamento por escrito.

- El Departamento de Energía, la agencia NOAA, el Servicio Geológico y otras agencias relacionadas con la temática deben establecer un programa conjunto de investigación para sistematizar la información científica y brindar informes científicos basados en el enfoque ecosistémico de las áreas sujetas a exploración.

- La Academia Nacional de Ciencias debe evaluar regularmente los programas de estudio del Gobierno en el área, preferiblemente en intervalos de cinco años.

- Junto con la agencia NOAA, la nueva Oficina de Concesiones y Ciencia Ambiental debe desarrollar programas de monitoreo ambiental o una serie de protocolos para que las compañías de petróleo y gas implementen en los sitios de concesión una vez que comienzan las actividades de exploración. Las áreas de interés ecológico y las áreas donde falta información ambiental deben ser sometidas a programas de monitoreo. El monitoreo debe ser realizado de manera que sea verificable de modo independiente y permita la comparación entre sitios individuales. Las Compañías deben brindar toda la información del monitoreo al gobierno federal.

- La agencia NOAA y otras agencias deben actuar como agencias de cooperación en las revisiones que lleva adelante la agencia EPA sobre las actividades de producción de energía, incluidos los planes de exploración y desarrollo y las solicitudes de perforación.

- Con respecto a la evaluación y gestión del riesgo, la exploración y producción de energía en aguas profundas implica riesgos para los que ni la Industria ni el Gobierno han estado adecuadamente preparados, pero para los que pueden y deben estar preparados en el futuro.

\subsection{Mejorar la planificación y la capacidad de respuesta}

La Comisión (2011) señaló tres puntos críticos o lagunas en la capacidad de respuesta del Gobierno: 
a) la falta de planificación eficaz sobre la contención de un derrame a gran escala, difícil de contener en aguas profundas del mar o potencialmente, en el Ártico;

b) la dificultad de coordinación entre funcionarios estaduales y locales para dar una respuesta adecuada; $\mathrm{y}$

c) la falta de información y conocimiento con respecto a la eficacia de las medidas de respuesta específicas, como los dispersantes y los diques o bermas.

La revisión y planificación ambiental actualmente se realiza en diferentes niveles entre el Gobierno y la Industria. A continuación, se sintetizan las principales recomendaciones con respecto a este punto que dictó la Comisión (2011), seguidas de una breve explicación:

Recomendación $\mathrm{N}^{\circ}$ 1: Análisis riguroso y transparente de los derrames para dar mejor respuesta.

Se necesita un nuevo proceso de revisión de los planes de respuesta a los derrames. Toda la información crítica y los escenarios de derrame deben ser incluidos en los planes de respuesta, se debe asegurar que los operadores puedan desarrollar las capacidades que indican en sus planes de respuesta.

Recomendación $\mathrm{N}^{\mathrm{o}}$ 2: La agencia EPA y la Guardia Costera deben establecer planes y procedimientos para responder ante un "Derrame de Significatividad Nacional”.

Se deben seguir los siguientes pasos:

- Desarrollar planes y procedimientos para tomar en cuenta los impactos en la salud humana durante un Derrame de Significatividad Nacional y reformar el Plan de Contingencia Nacional para que incluya distintos procedimientos para tomar en cuenta ante estos impactos.

- Aumentar la estructura del Equipo de Respuesta Nacional y del Equipo de Respuesta Regional para establecer marcos adicionales con el objetivo de brindarayuda científica inter agencia y experticia en el desarrollo de políticas.

- Crear un protocolo de comunicaciones que tome en cuenta la participación de funcionarios de alto nivel que pueden estar menos familiarizados con el Plan de Contingencia Nacional y crear un centro de comunicaciones con el Comando de Incidentes Nacional. A su vez, es crítico el control ecológico posterior para entender el impacto de las actividades y para facilitar un enfoque adaptativo a la gestión ambientalaparte del centro de información conjunto establecido con la parte responsable- para ayudar a transmitir información consistente y completa al público.

- Reforzar el involucramiento Estadual y Local.

En el accidente de la plataforma Deepwater Horizon, los funcionarios de nivel estadual no pudieron participar eficazmente porque los funcionarios federales competían con ellos, 
por lo que el control del derrame terminó siendo menos eficiente en su totalidad (Comisión, 2011).

Recomendación $N^{\circ}$ 3: Participación pública. La agencia EPA y la Guardia Costera deben promover la participación ciudadana a nivel estadual y local en la planificación y respuesta ante los derrames, de modo similar al Consejo de Opinión Regional de Ciudadanos que estableció la Ley sobre Contaminación por Hidrocarburos (OPA).

El Consejo debe estar representado por ciudadanos con intereses en el área, por ejemplo la pesca y el turismo, e incluir representantes de trabajadores de la industria del petróleo y del gas, en calidad de miembros sin derecho a voto. Se recomienda que sea obligatorio que los funcionarios encargados de la regulación federal consulten al Consejo sobre temas relevantes, que los operadores permitan que el Consejo acceda a los informes y que cuando la Industria y el Gobierno no sigan las recomendaciones del Consejo, expresen sus razones al Consejo por escrito.

Recomendación $\mathrm{N}^{\circ}$ 4: El Congreso Nacional debe establecer la financiación obligatoria para la investigación sobre la respuesta ante derrames de petróleo y otorgar incentivos al sector privado para que lleve adelante la investigación.

El Congreso no había utilizado siquiera la mitad del monto de dinero que autoriza la ley OPA al momento del accidente en la plataforma Deepwater Horizon (Comisión, 2011). Incluso, las compañías petroleras más importantes invirtieron mínimos recursos para la investigación interna y el desarrollo de tecnología para responder ante los derrames. En general, las organizaciones que se ocupan de remover los derrames de hidrocarburos no tienen fondos. Luego de la tragedia de la plataforma Deepwater Horizon, surgieron algunas propuestas, por ejemplo, máquinas para limpiar las playas, sistemas de dispersantes subacuáticos y técnicas de quema in situ (Comisión, 2011).

Se debe establecer un Organismo Consultivo, formado por expertos de oficinas del Departamento del Interior, del Servicio Geológico, del Departamento de Energía, de la agencia EPA, y la agencia NOAA, así como miembros de la Academia, la Industria y ONG’s para desarrollar una agenda de investigación y el camino a seguir.

Recomendación No 5: Dispersantes y bermas.

La agencia EPA debe actualizar y revisar periódicamente sus protocolos de evaluación de los dispersantes y modificar el proceso de pre-aprobación para incluir la duración, el alcance espacial y el volumen del derrame.

La decisión acerca de utilizar dispersantes es complicada, si son efectivos, llegará menos petróleo a la costa, pero se esparcirá más petróleo dispersado en la columna de agua. Se debe investigar sobre los efectos del uso de los dispersantes y sobre el desarrollo de dispersantes menos tóxicos (Comisión, 2011). 
Con respecto a las bermas, la Guardia Costera debe asentar por escrito en una guía que las bermas en el mar y barreras similares no sean generalmente autorizadas como una respuesta frente a un derrame de petróleo en el Plan de Contingencia.

Estas barreras implican tiempo y costo en su construcción, fue la medida menos efectiva utilizada en el caso de la plataforma Deepwater Horizon y se basó más en la demanda popular que en una evaluación científica (Comisión, 2011).

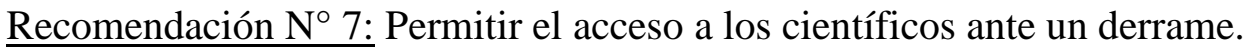

La Guardia Costera debe permitir el acceso a los científicos a la zona de respuesta inmediatamente luego de que se produzca un derrame para que puedan llevar a cabo una investigación científica independiente, esto no sucedió en el caso de la plataforma Deepwater Horizon.

\subsection{Mejorar la capacidad de contención de los Pozos}

Ésta fue la falla más grave en el caso de la plataforma Deepwater Horizon, no pudo contenerse el derrame del pozo. El Plan de Exploración Inicial presentado por la Compañía BP identificaba sólo una respuesta: un pozo de alivio, cuya construcción demandaría meses.

El Equipo de Respuesta Nacional debe desarrollar junto con el gobierno federal cantidades estimadas precisas del volumen del derrame apenas se produce e intentar controlarlo en la fuente. Se requiere que el Proceso de Diseño y Aprobación de los Pozos sea más exigente.

La tecnología, las leyes, las regulaciones y prácticas para contener, responder y limpiar los derrames están muy retrasadas con respecto a los riesgos reales asociados con la perforación en aguas profundas, en reservorios de alta presión de petróleo y gas ubicados lejos en el mar y a mucha profundidad. La Comisión concluyó que el Gobierno debería dar por terminada esta laguna y la Industria debe apoyar el esfuerzo, en lugar de resistirlo. El conocimiento científico sobre las condiciones en ambientes sensibles en aguas profundas del Golfo, en los hábitats costeros de la región y en áreas propuestas para perforación, como el Ártico está poco desarrollado. Lo mismo sucede con el conocimiento científico con respecto a los impactos que los derrames de petróleo producen en el ambiente (Comisión, 2011).

\subsection{Superar los Impactos del Derrame y Restaurar el Golfo}

El derrame de la plataforma Deepwater Horizon causó un daño significativo a los recursos naturales y hábitats en la costa del Golfo y en el ambiente marino de aguas profundas (Comisión, 2011). En EE.UU., los daños a los recursos naturales se evalúan de acuerdo con las disposiciones establecidas al respecto en la ley OPA. La reparación debe realizarse in-situ y en especie si fuera posible, cinco Estados del Golfo fueron afectados en el caso de la plataforma Deepwater Horizon, el mayor daño ocurrió en el Estado de Luisiana. Los 
daños en el ambiente marino provocado por este accidente no tienen precedentes (Comisión, 2011).

La compensación de conformidad con las disposiciones de la ley OPA debe ser transparente y apropiada. Se debe designar a un auditor científico independiente para llevar adelante la tarea de evaluar el daño provocado a los recursos naturales. Se estima que restaurar el Golfo en su totalidad requerirá entre 15.000 y 20.000 millones de Dólares, un mínimo de 500 millones de Dólares por año, en un período de 30 años. Se requiere una fuente confiable de financiamiento a largo plazo para lograr la restauración. Actualmente distintas fuentes otorgan financiamiento a los Estados para llevar adelante la restauración, pero ninguno para la restauración costera y marina del Golfo (Comisión, 2011).

El Congreso ya ha comenzado a considerar otras potenciales fuentes de financiamiento, incluso a gravar la producción del petróleo con impuestos de barreras para arancelarias y a cobrar regalías más elevadas. El Congreso debería dedicar el 80\% de las penalidades de la Clean Water Act (Ley de Agua Pura) para la restauración a largo plazo del Golfo de México. Se formó el grupo de tareas denominado Gulf Coast Ecosystem Restoration Task Force (Grupo de Tareas de Restauración del Golfo de México) para ocuparse de este asunto.

El Congreso debe conformar un Consejo federal-estadual de Restauración Ecosistémica de la Costa del Golfo. Se podría tener en cuenta el Consejo de Beneficiarios del Derrame que se formó luego del accidente del Buque Exxon Valdez. Los proyectos podrían ser categorizados de diversas maneras, por ejemplo: por hábitat (estuarios, praderas marinas, humedales, arrecifes de coral); por objetivo (productividad biológica y función del ecosistema, mejorar la resiliencia, restaurar las pesquerías); o por tipo de proyecto específico (desvío de ríos, enriquecimientos de playas). Las decisiones restaurativas deben tener basamento científico (Comisión, 2011).

\subsection{El aseguramiento de la Responsabilidad Financiera}

En el caso del derrame de la plataforma Deepwater Horizon, la compañía BP colocó 20.000 millones de Dólares en garantía para compensar a las personas físicas y jurídicas. Pero si se hubiera tratado de una compañía menos solvente, habría sido más difícil cubrir la compensación.

El límite de responsabilidad en la ley OPA es de 75 millones de Dólares, salvo dolo, violación de la legislación federal u omisión de informar el accidente. El límite es bajo, la Comisión (2011) afirma que es necesario aumentar este límite. Las demandas de hasta mil millones de Dólares pueden ser pagadas por el Fondo Fiduciario de Derrame de Hidrocarburos que actualmente es financiado por el 8\% de la barrera pre-arancelaria que se aplica al petróleo nacional y al importado.

Esta circunstancia presenta dos inconvenientes: 
- Falta de Incentivos de Seguridad Adecuados: Las compañías no adoptan precauciones de seguridad costo-efectivas.

- Compensación Inadecuada de Daños: los daños en este caso totalizan diez mil millones de Dólares.

El Congreso debería aumentar significativamente el límite de responsabilidad y la responsabilidad financiera en el caso de las plataformas marinas. En EE.UU. se acepta la limitación de responsabilidad, la responsabilidad no es integral. Durante los intentos legislativos que hubo para incrementar el límite de responsabilidad, se argumentó que este incremento podría traer aparejado que los aseguradores dejaran el mercado, lo que significaría que diversas compañías pequeñas e independientes de la industria, por consecuencia también dejaran el mercado. El contra-argumento es que las compañías petroleras deben soportar los costos sociales de sus actividades, y si estos costos son muy grandes o impredecibles para ser asegurables, entonces las compañías deberían dejar el mercado (Comisión, 2011).

Una opción para mantener a compañías independientes en el Mercado consiste en conformar un pool de seguros mutual. Otra opción que recomienda la Comisión (2011) es realizar un aumento gradual de los límites de responsabilidad, con el argumento que le dará a la industria del seguro un período de ajuste. Finalmente, se puede estimular que las compañías más pequeñas formen uniones transitorias de empresas con compañías más grandes.

\subsection{El compromiso del Congreso para asegurar la perforación eficiente en el Mar}

La Comisión (2011) ha elaborado las siguientes recomendaciones en torno al rol del Poder Legislativo en la actividad:

Recomendación $\mathrm{N}^{\circ}$ 1: El Congreso debe involucrarse sistemáticamente en asegurar la seguridad y la protección ambiental de las perforaciones en la plataforma continental.

El Congreso debe aumentar su atención sobre la actividad. En primer lugar, se deben controlar los riesgos de seguridad y ambientales. En segundo lugar, se debe requerir a las Comisiones pertinentes del Congreso que realicen una audiencia anual sobre el estado de la tecnología, la aplicación del proceso de seguridad y la protección ambiental para asegurar que el Congreso mantenga la atención sobre esta actividad.

Hay superposición de atribuciones entre las Comisiones de Recursos Naturales y la de Energía en el Congreso. Ninguna Comisión se encarga directamente de estudiar los impactos de seguridad y ambientales de la extracción de hidrocarburos en el mar, empezaron a hacerlo recién luego del accidente de la plataforma Deepwater Horizon, sí muchas Comisiones se ocupan de las regalías que la actividad deja (Comisión, 2011). La Comisión recomendó la creación de una Autoridad de Seguridad Marina y que la Comisión del Congreso que analice estos temas la audite. 
El Congreso debe requerir a la Secretaría del Interior que remita un informe público anual sobre las actividades de desarrollo de la energía en el mar a las respectivas Comisiones del Congreso. El informe debe basarse en el progreso del Departamento en la mejora de las regulaciones de seguridad y los pasos tomados por la Industria y el Gobierno para mejorar la gestión de las instalaciones. El informe también debe detallar las áreas en las que el Departamento cree que la Industria no está haciendo todo lo necesario para promover la seguridad y el cuidado del ambiente y aquellas áreas en las que sería necesario dictar legislación adicional.

Recomendación $\mathrm{N}^{\circ}$ 2: El Congreso debe priorizar la sanción de legislación para crear un mecanismo para que los operadores de petróleo y gas otorguen financiamiento a las agencias que regulan el desarrollo de la exploración y explotación de petróleo y gas en el mar, la oficina BOEMRE actualmente recibe dinero de la Industria.

A continuación, en el Cuadro $\mathrm{N}^{\mathrm{o}} 1$ se sintetizan las variables identificadas en el Informe de la Comisión (2011):

\section{Cuadro $\mathbf{N}^{0} 1$}

\section{Variables identificadas en el Informe de la Comisión (2011)}

\begin{tabular}{|l|l|}
\hline Informe de la Comisión (2011) & Medidas a implementar \\
\hline El rol del Gobierno & $\begin{array}{l}\text {-reforma normativa } \\
\text {-reforma institucional (división de atribuciones: } \\
\text { seguridad, concesiones, ganancias). }\end{array}$ \\
\hline El rol de la Industria & -creación de una oficina de seguridad. \\
\hline Protección del ambiente & $\begin{array}{l}\text {-eliminar: } \\
\text { tiering, } \\
\text {. exclusiones categóricas, } \\
\text {. concesiones en áreas extensas. } \\
\text {-elaborar Guía NEPA. } \\
\text {-establecer proceso de interconsulta científica } \\
\text { para demarcar zonas donde se prohíba explorar. } \\
\text {-expandir el sistema de observación integrada del } \\
\text { océano. }\end{array}$ \\
\hline
\end{tabular}




\begin{tabular}{|c|c|}
\hline $\begin{array}{l}\text { Mejorar la planificación y la } \\
\text { capacidad de respuesta }\end{array}$ & $\begin{array}{l}\text {-mejorar coordinación federal-estadual. } \\
\text {-mejorar conocimiento científico sobre las } \\
\text { medidas de respuesta. } \\
\text {-fomentar la participación pública. } \\
\text {-mejorar conocimiento científico sobre } \\
\text { dispersantes y bermas. } \\
\text {-permitir acceso a los científicos al lugar de los } \\
\text { accidentes. }\end{array}$ \\
\hline $\begin{array}{l}\text { Mejorar la capacidad de } \\
\text { contención de los pozos }\end{array}$ & -controlar derrames en la fuente. \\
\hline La restauración & $\begin{array}{l}\text {-in situ y en especie. } \\
\text {-conformar Consejo federal-estadual de } \\
\text { restauración ecosistémica. }\end{array}$ \\
\hline Responsabilidad financiera & $\begin{array}{l}\text {-aumentar el límite de responsabilidad. } \\
\text {-conformar un pool de seguros mutual. }\end{array}$ \\
\hline El rol del Congreso & $\begin{array}{l}\text {-controlar los riesgos de seguridad y ambientales. } \\
\text {-requerir que se le envíe un informe público anual. } \\
\text {-crear un mecanismo para que las empresas del } \\
\text { rubro financien a las agencias regulatorias. }\end{array}$ \\
\hline
\end{tabular}

Fuente: Elaboración propia.

\section{El accidente de la Plataforma Montara}

\section{Mapa $\mathbf{N}^{\circ} 2$}

\section{Ubicación de la Plataforma Montara}




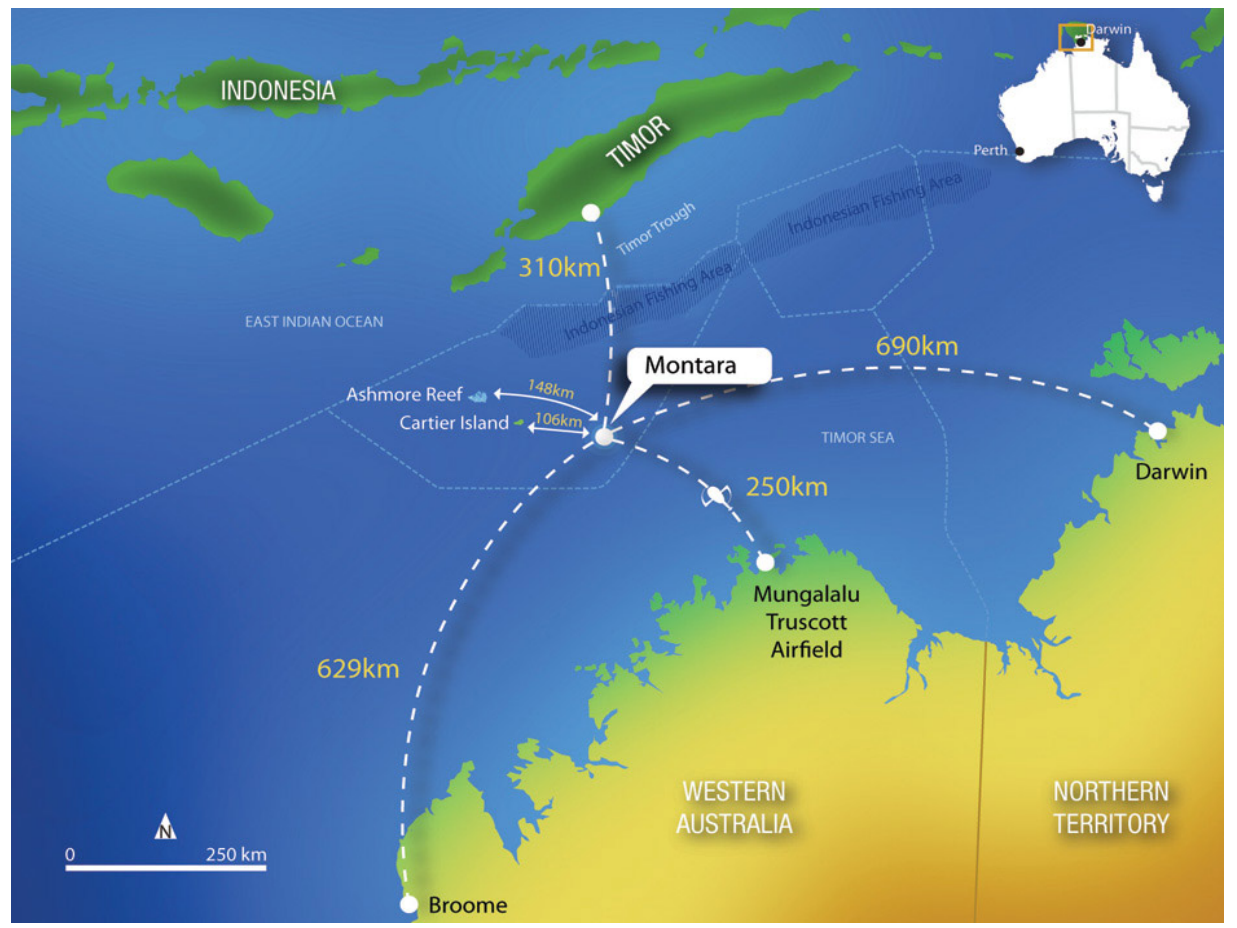

Fuente: http://www.au.pttep.com/our-business/montara/

\section{Fotografía $\mathbf{N}^{\circ} 7$}

\section{El accidente en la Plataforma Montara}

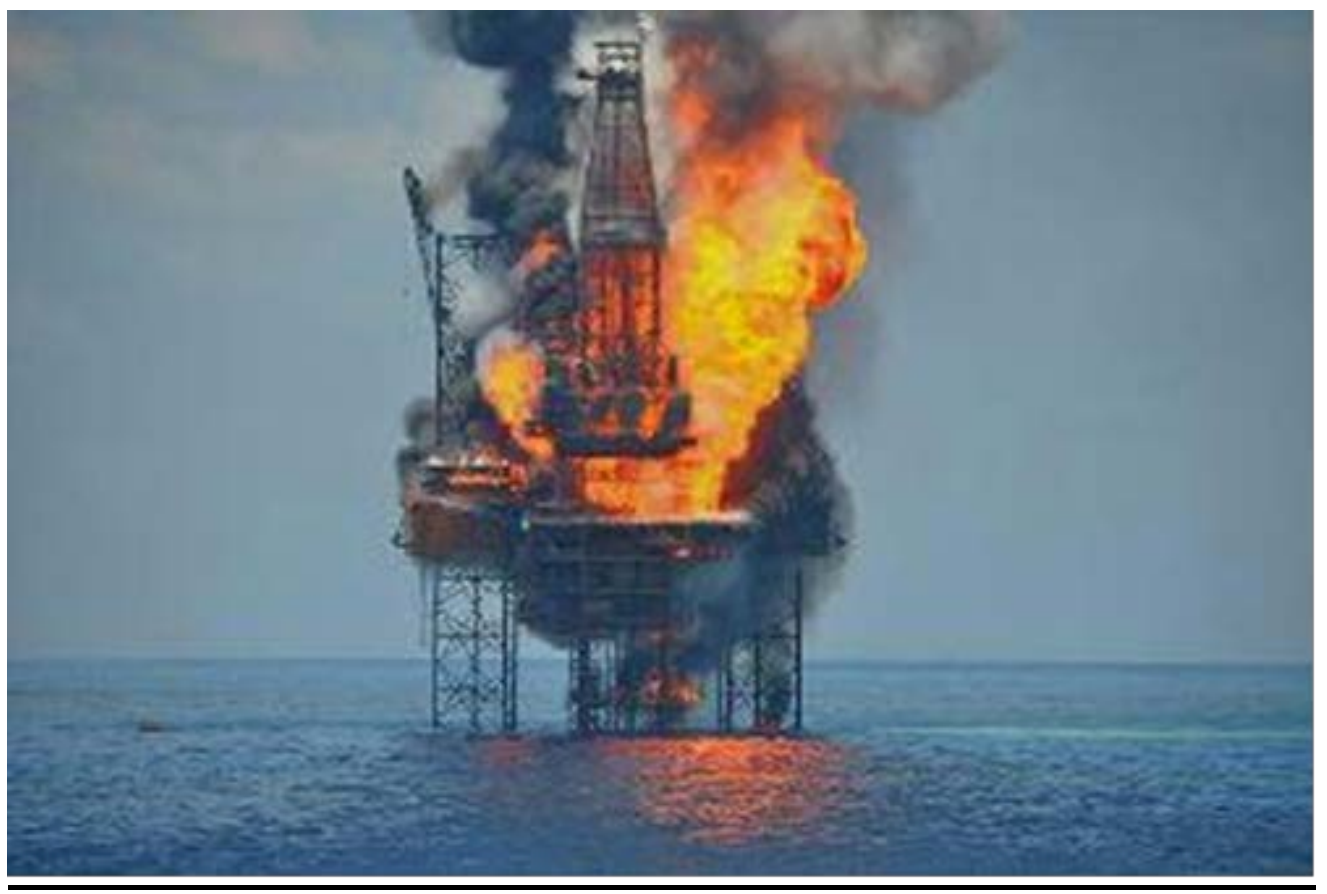

Fuente: http://www.montaradisaster.blogspot.com.ar/ 
El accidente de la plataforma Montara fue un caso insignia de contaminación transfronteriza entre Australia e Indonesia, cuyas consecuencias aún no fueron resueltas (Lyons, 2015). La plataforma Montara estaba ubicada en el Mar Timor a 140 millas náuticas de la costa de Australia y 50 millas náuticas de la ZEE de Indonesia. El derrame de hidrocarburos se produjo el 21 de agosto de 2009 y se extendió durante 74 días. Debido a que no podía detenerse el derrame, se trasladó a otra plataforma perforadora para que realizara un pozo en el lecho para aliviar la presión e interrumpir el derrame, esta plataforma comenzó a perforar el 11 de septiembre de 2009, recién el $1^{\circ}$ de noviembre de 2009 logró algún éxito (Comisión Montara, 2010) ${ }^{13}$. Se utilizaron 3400 barriles de lodo pesado para detener el derrame, fue el tercer derrame de petróleo en Australia y el peor derrame del país en la industria de petróleo en el mar. Según el Departamento Australiano de Recursos, Energía y Turismo se derramaron 2.000 barriles por día (equivalentes a 318.000 litros). En total, se utilizaron 184.00 litros de dispersantes de seis tipos diferentes, que habían sido pre-aprobados por el Plan Nacional Australiano. El informe de la Comisión de Investigación de Montara fue hecho público el 24 de noviembre de 2010 junto con una respuesta borradora por parte del Gobierno.

A nivel histórico, Australia e Indonesia sostuvieron largas y complejas negociaciones en torno al Mar Timor y sus recursos vivos y no vivos reflejados en la negociación de varios tratados sobre límites (Lyons, 2015). En un primer momento, estos tratados aplicaban sobre parte del lecho marino, más adelante en 1997 se firmó el Tratado que estableció el límite de la Zona Económica Exclusiva (ZEE) y también diferentes acuerdos sobre pesquerías, incluso se concedió acceso a pescadores de Indonesia a una zona de la ZEE, y se realizó un acuerdo para la exploración y explotación conjunta de hidrocarburos. Existen áreas donde la jurisdicción se solapa, donde Australia tiene derechos soberanos sobre los recursos del lecho marino, pero Indonesia tiene derechos soberanos sobre los recursos de la columna de agua por encima del lecho marino. El derrame provocado por el accidente ocurrido en la Plataforma Montara afectó estas áreas y también áreas donde Indonesia tiene jurisdicción tanto sobre el lecho marino, como sobre la columna de agua. El derrame comenzó en la ZEE australiana y se expandió primero a la columna de agua -se extiende verticalmente- de la ZEE de Australia, luego las imágenes satelitales mostraron que se extendió a Indonesia.

El Informe de la Comisión de Investigación de la plataforma Montara concluye que los errores de la compañía eran sistemáticos. La causa primaria del derrame parece haber sido una falla de la primera y segunda barreras de control de los pozos y las cubiertas de cemento, que no cumplieron con los Estándares de Construcción de la Empresa propietaria del Pozo. En 2009 se habían suspendido las operaciones del pozo durante cuatro meses, cuando se reanudaron las operaciones, la única barrera secundaria que había

13 Borthwick, David. Comisión Montara de Información, “Informe de la Comisión Montara de Investigación”. Australia, $2010 . \quad$ Recuperado de https://industry.gov.au/resource/UpstreamPetroleum/MontaraInquiryResponse/Documents/MontaraReport.pdf [Consulta: julio de 2017]. 
sido instalada, fue removida. La explosión ocurrió quince horas después de que la primera barrera, que no había sido evaluada y no tenía protección secundaria, fuera dejada expuesta. Es decir que en este caso, según el Informe se concluye, que el accidente no fue consecuencia de un infortunio, sino algo que iba a ocurrir. Se señala que fue un error permitir que el pozo operara sólo con una barrera durante 36 horas (Lyons, 2015).

El Gobierno de Australia, luego del accidente, de forma similar a lo que sucedió en EE.UU. luego del accidente de la plataforma Deepwater Horizon, respondió con una serie de medidas. Una de las medidas fue la creación de una institución nacional independiente que tiene a su cargo la regulación de las actividades hidrocarburíferas en el mar, que se denomina la Autoridad Nacional de Gestión de Seguridad y Ambiente de los Hidrocarburos en el Mar (NOPSEMA, por sus siglas en inglés) y la re-organización institucional de las autoridades comprendidas. Esta institución debe velar por la seguridad, la integridad de los pozos y el cumplimiento de los requisitos ambientales.

Se sostiene que la falla radicó en la implementación del régimen legal, debido a que el régimen ya existente para controlar el monitoreo de las operaciones de las plataformas era adecuado. En Australia cuentan con una ley ambiental denominada Environmental Protection and Biodiversity Consevation Act 1999 (EPCB) ${ }^{14}$ y una ley específica sobre la regulación de la exploración y explotación de hidrocarburos en el mar denominada Offshore Petroleum Act (OPA) 2006, que aunque fue promulgada en 2006, entró en vigor en 2008 con una modificación en su denominación, Offshore Petroleum and Greenhouse Gas Storage Act (OPGGS) ${ }^{15}$. En el informe se sostiene que las disposiciones de ambas leyes no debían superponerse. Por ejemplo, se sostiene que el sistema de lucha contra la explosión fue eficiente. Básicamente, se recomienda controlar y verificar por escrito la instalación y remoción de las barreras y se concluye que siempre debe haber un mínimo de dos barreras. Asimismo, se dispone un incremento en las multas en caso de omisión en el respeto de las medidas de seguridad. Del mismo modo, se recomienda que en caso de un próximo accidente, las decisiones a tomar no deberían reposar sólo en los operadores y que se debe mantener informados a los ciudadanos.

Se destaca que en la Constitución australiana hay una referencia a la exploración en el mar, ya que existe la denominada "Offshore Constitutional Settlement" que dispone sobre la distribución de competencias a nivel federal y estadual en el país. Se crean dos autoridades, una que se encarga de los temas administrativos y otra autoridad denominada “Autoridad Conjunta” que determina en qué áreas se permite la exploración y explotación de hidrocarburos en el mar.

Con respecto al monitoreo de los daños ambientales generados por el derrame, en el Informe de la Comisión australiana se señala que no hubo un estimativo por día de la

\footnotetext{
${ }^{14}$ Australia. Environmental Protection and Biodiversity Consevation Act 1999 (EPCB). 
cantidad de petróleo que se derramaba y los términos del programa de monitoreo científico recién se acordaron el 9 de octubre de 2009. Esto se debe a que Australia no cuenta con legislación que regule los pagos por servicios ecosistémicos. Los servicios ecosistémicos han sido definidos en la Evaluación de los Ecosistemas del Milenio (2015) elaborados por la $\mathrm{ONU}^{16}$ se los define como los beneficios que las personas obtienen de la naturaleza. El Gobierno de Indonesia reclama 2.4 mil millones de Dólares.

\section{4. ¿Cambio de paradigma ambiental?}

De la lectura del Informe presentado por la Comisión Montara, en términos generales, se desprende que el Informe tuvo un enfoque más técnico y menos holístico en términos ambientales que el Informe que fue preparado unos años después a consecuencia del accidente en la plataforma Deepwater Horizon que se analizó previamente. Es decir, en el Informe preparado por la Comisión australiana se aprecia su acotación sólo al accidente. Por otro lado, el informe elaborado en EE.UU. da cuenta de un cambio de paradigma ambiental en el país luego del accidente. En otras palabras, el Informe estadounidense no se limita a cuestiones técnicas, sino que plantea cuestiones de índole filosófica y ambiental, es decir, se aborda el tema desde una mirada en mayor medida ambientalista. Se toma mayor responsabilidad, se plantea toda una serie de medidas de restructuración de la exploración y explotación hidrocarburífera en el mar, considerándola como una actividad que impacta en toda la sociedad, sin reducir el tema a cuestiones técnicas del ámbito de la ingeniería a solucionar, como se desprende en mayor medida del Informe presentado por los australianos.

En el Informe australiano se afirma que la responsabilidad del propietario/operador debe ser integral. Sin embargo, el informe australiano cuenta con menor basamento en el Derecho Ambiental, porque se basa en menor medida en la prevención-precaución, es decir en la etapa previa al daño ambiental; tiene mayor basamento en la etapa posterior al daño ambiental, por ejemplo menciona al principio "contaminador-pagador”. Tampoco se hace alusión a la evaluación de impacto ambiental (EIA) y a otras medidas que se mencionan en el informe estadounidense al respecto; por ejemplo, la eliminación de las exclusiones categóricas -es decir, el hecho que algunas actividades, como la exploración y explotación de hidrocarburos en el mar esté exenta de la EIA-, la eliminación del procedimiento denominado tiering que implica que las EIAs se realicen en ámbitos geográficos muy extensos sujetas a promesas de futuras EIAs más acotadas en el tiempo que luego nunca se realizaban. Tampoco se menciona en el informe australiano la implementación de las AMPs o la PEM.

\section{Conclusiones}

\footnotetext{
${ }^{16}$ Evaluación de los Ecosistemas del Milenio (2015).

Recuperado de http://www.millenniumassessment.org/es/About.html\#1 [Consulta: julio de 2017].
} 
El análisis de los informes de las Comisiones que estudiaron los respectivos accidentes de plataformas marinas en el Mar Timor y en el Golfo de México pone de relieve las considerables implicancias que la exploración y la explotación de hidrocarburos en el mar provocan en el ambiente.

En particular, la falta de control por parte del Gobierno y la necesidad de reparar el ambiente o indemnizar en su defecto el daño ambiental transfronterizo generado son puntos críticos. Ante todo es necesario un régimen ambiental que actúe ex ante, en la etapa preventiva y precautoria, antes de que las plataformas sean instaladas.

El accidente de la plataforma Deepwater Horizon en EE.UU. ha introducido un cambio de paradigma ambiental en el país. De la lectura de las Recomendaciones elaboradas por la Comisión que estudió el accidente de la plataforma Deepwater Horizon en EE.UU. puede concluirse con respecto al rol del Gobierno, que se recomendó una reforma normativa y una reforma institucional con el objeto de crear tres oficinas diferentes, una con atribuciones sobre la seguridad, otra sobre las concesiones y otra sobre las ganancias que genere la actividad; anteriormente una misma oficina se encargaba de gestionar toda la actividad. En este sentido, se ha optado por reemplazar la denominación "minerales" que se incluía en el nombre de la Agencia que se dedicaba a regular esta temática (MMS) por una denominación que contiene la palabra “Océano” (BOEMRE), que actualmente es una Agencia que no sólo gestiona la exploración y explotación de hidrocarburos en el mar, sino también la generación de energía renovable en el mar. En relación con el rol de la Industria, se propuso la creación de una oficina de seguridad en su seno para desarrollar la responsabilidad empresarial.

En lo relativo a la protección del ambiente, las conclusiones de la Comisión indicaron que la actividad de exploración y explotación de hidrocarburos en el mar debe ser sometida previamente a una EIA, es decir, deben eliminarse las exclusiones categóricas en este sentido y no se debe permitir la realización de EIAs que comprendan áreas muy extensas (tiering). Asimismo, se asentó el compromiso de gestionar integral y ambientalmente el mar mediante la PEM que involucre a diversas agencias gubernamentales $\mathrm{y}$ principalmente a las científicas, para desarrollar las AMPs. Del mismo modo, se estableció que se debe expandir el sistema de observación integrada del océano.

Se concluyó que se debe establecer un proceso de consulta interagencia formal con fundamento científico, es decir, que incluya verbigracia la opinión vinculante de NOAA, la agencia científica que se ocupa de los temas oceánicos y atmosféricos para delimitar las AMPs, y establecer las zonas donde no se puede realizar la exploración y explotación de hidrocarburos.

Con respecto al mejoramiento de la planificación y capacidad de respuesta, se afirmó que se deben mejorar la coordinación federal-estadual y el conocimiento científico sobre las medidas de respuesta, además de fomentar la participación ciudadana. Se concluyó que el Congreso debe controlar los riesgos de seguridad y ambientales, requerir que se le 
remita un informe público anual sobre la situación de la actividad exploratoria y extractiva de hidrocarburos en el mar y crear un mecanismo para que las empresas del rubro financien a las agencias regulatorias.

En relación con el Informe elaborado por la Comisión australiana que estudió el accidente en la plataforma Montara, se destaca que al referirse a la valoración del daño ambiental para llevar adelante su compensación, se explicó que no ha podido ser debidamente cuantificado debido a que en Australia no está legislada la valoración de los servicios ecosistémicos.

Del análisis comparativo de ambos informes de las Comisiones, se desprende que el informe australiano se ha centrado principalmente en cuestiones relativas a la etapa posterior al daño ambiental, no así en la etapa preventiva-precautoria, debido a que no menciona en el informe a la EIA, ni a las AMPs, ni a la participación ciudadana como en el caso del informe preparado por la Comisión estadounidense.

El accidente ocurrido en aguas australianas, a pesar de su magnitud, de la contaminación transfronteriza que generó en Indonesia, no ha logrado un cambio de actitud ni de paradigma en el Gobierno ni en la sociedad australiana. Ya que se adujo que las causas del accidente se debieron a falencias técnicas y en ningún momento se mencionaron los daños ambientales.

Bibliografía:

- Borthwick, David. Comisión Montara de Información, “Informe de la Comisión Montara de Investigación”. Australia, 2010.

Recuperado de

https://industry.gov.au/resource/UpstreamPetroleum/MontaraInquiryResponse/Docume nts/Montara-Report.pdf [Consulta: julio de 2017].

- Comisión Nacional del Derrame de Hidrocarburos de la Plataforma BP Deepwater Horizon y Perforación en el mar, "Deep Water. El Desastre de Hidrocarburos en el Golfo y el Futuro de la Perforación en el Mar. Informe al Presidente. Recomendaciones de la Comisión Nacional del Derrame de Hidrocarburos de la Plataforma BP Deepwater Horizon y Perforación en el Mar”. EE.UU, 2011.

Recuperado de

https://cybercemetery.unt.edu/archive/oilspill/20121210200707/http://www.oilspillcom mission.gov/sites/default/files/documents/OSC_Deep_Water_Summary_Recommendati ons_FINAL.pdf [Consulta: julio de 2017].

- Ferrara, P. (2015). El Offshore en la República Argentina. Revista de Doctrina. Jurisprudencia, Legislación y Práctica de Derecho Administrativo, 99. Abeledo Perrot, 685-908. 
- Lyons, Y. (2015). Transboundary pollution from offshore activities: a study of the Montara offshore oil spill. En Jayakumar, S., Koh, T. \& Beckman, R. (Eds.), Transboundary Pollution: Evolving Issues of International Law and Policy (pp.162189). Londres: Edwar Elgar publishing.

- Nonna, S. (1998). La Industria Petrolera: Compromiso con el Ambiente. En El Rumbo Ambiental en la Argentina (pp. 125-190). Buenos Aires: Ciudad Argentina.

- OECD (2016). The Ocean Economy in 2030. Paris: OECD Publishing. DOI: http://dx.doi.org/10.1787/9789264251724-en

- Radovich, V. (2016). Petróleo y gas en el mar. Regulación ambiental en la República Argentina. Revista de la Facultad de Derecho y Ciencias Políticas-Universidad Pontificia Bolivariana; Año: 2016 vol. 46 p. 261 - 274.

- Roach, A. (2013). International Standards for Offshore Drilling. En Nordquist H. Marion (Ed.), The Regulation of Continental Shelf Development: Rethinking International Standards (pp. 105-150). Leiden: Martinus Nijhoff Publishers.

- Silva Oliveira, L. \& Silva Salvio, M. (2015). A Exploração Offshore e a Proteção do Meio Ambiente Marinho: Um desafio para o Regime Jurídico Europeu. En Costa de Oliveira, C. (Coord.), Meio Ambiente Marino e Direito (pp.169-188). Curitiba: Juruá editora.

Legislación:

Internacional:

- Convención de Responsabilidad Civil por Daño por Contaminación por Hidrocarburos resultante de la Exploración y Explotación de Recursos Minerales del Lecho Marino (“CLEE 1977”), adoptada 1 mayo 1977 (no está en vigor).

- Convenio Internacional sobre Cooperación, Preparación y Lucha contra la Contaminación por Hidrocarburos (“OPRC 1990”), adoptado 30 de noviembre de 1990, 1891 UNTS 51 (entró en vigor 13 de mayo de 1995).

- Convención sobre la Diversidad Biológica (“CDB”), adoptada 5 junio de 1992, 1760 UNTS 79 (entró en vigor 29 de diciembre de 1993).

Nacional:

- Australia. Environmental Protection and Biodiversity Consevation Act 1999 (EPCB).

- Australia. Offshore Petroleum and Greenhouse Gas Storage Act 2008 (OPGGS).

- EE.UU. Ley OPA.33 U.S.C. §2701 et seq., 1990.

Uruguay. Decreto reglamentario 316/11, Aprobación de las Bases para el proceso de selección de empresas petroleras para la exploración y explotación de hidorcabruros en costa afuera de la República Oriental del Uruguay para la Ronda Uruguay II, que 
incluyen el respectivo modelo de contrato. Registro Nacional de Leyes y Decretos, tomo 1 , semestre 2, 28/10/2011. 